\title{
Term Lowbirth Weight Neonate: Maternal Factors
}

\author{
Bashar Mukhlif Khalaf ${ }^{1}$, Zuhair Idreas Mohammed ${ }^{1}$, Nada Hasan Ali ${ }^{1}$ \\ ${ }^{1}$ Board Dr. Pediatrics, Department of Pediatrics, Al-qayarh General hospital, Mosul, Iraq
}

\begin{abstract}
The current research aims to detect the maternal risk factors that influence the birth weight of the babies. Risk factors related to the mothers like gestational age, maternal age, nutrition, and medical problems play a role in the delivery of infants with low birth weight. The sample consisted of 267 ladies give a birth to newborns. Mothers with less than or $=150 \mathrm{~cm}$ giving low birth weight babies $(62.3 \%)$ while those with more than $150 \mathrm{~cm}$ giving low birth weight babies $(37.7 \%)$. In the normal birth weight group, working mothers represent $(82.1 \%)$ while in normal birth weight group they represent $(17.4 \%)$. Mothers more than or $=35$ years old giving $(33.1 \%)$ normal birth weight babies. Young mothers less than 20 years old gave more low birth weight babies $(28.7 \%)$ than older mothers with more 20 years old.

The maternal risk factors of low birth weight babies include maternal age $<20$ years old, low maternal educational level, working mothers, smoking, pre-pregnancy weight $<50 \mathrm{~kg}$, maternal height $\leq 150 \mathrm{~cm}$, low socioeconomic status, inter pregnancy interval of less than one year, previous low birth weight babies, history of infertility and first week neonatal death, low rate of visiting to antenatal care centers.
\end{abstract}

Keywords: Low birth weight, risk factors, antenatal care, fetal growth.

\section{Introduction}

According to the WHO, low birth weight (LBW) is defined as the weight at birth of less than $2.5 \mathrm{~kg}$ whatever the gestational age ${ }^{1}$. While, very LBW (VLBW) is the infant weight $<1.5 \mathrm{~kg}$, and extremely LBW (ELBW), the infant $<1 \mathrm{~kg}{ }^{2}$.

LBW is considered a major health concern all over the world, particularly in developing countries. Around 25 million LBW infants are born per year, and $20 \%$ of them die globally ${ }^{1}$.

Infants who weigh less than 2,499 gm at birth are at twenty times more risk of neonatal death than those who weigh more than $2,500 \mathrm{gm}^{3}$.

\footnotetext{
Corresponding Author:

Bashar Mukhlif Khalaf,

Pediatrician Dr., Department of Pediatrics, Al-qayarh

General hospital, Mosul, Iraq

e-mail: basharmukhlif@gmail.com
}

The prevalence of low birth weight in in developed regions (7\%) while in developing countries $(16.5 \%)^{4}$.

There are many risk factors of LBW in developing countries include the age of the mother, maternal education, attendance of the antenatal care (ANC) follow-up, socioeconomic status, and maternal body mass index ${ }^{5}$.

In general, LBW is due to genetic, nutritional, obstetric, constitutional, prenatal maternal morbidities, drugs and toxins exposure, and ANC follow-up. In addition, other risk factors have also been reported like age of the mother, smoking, birth spacing, genital infections, anemia, stress, and ill health mothers 6 .

The aim of the study was to find the maternal risk factors for LBW in full term babies.

\section{Materials and Method}

This is a prospective cohort study that was carried out during the period from the $1^{\text {st }}$ of March 2019 till the $1^{\text {st }}$ of July 2019 that involving 267 ladies delivered at AL-Khansaa and Ibn-Alatheer Maternity and Children Teaching Hospitals in Mosulcity/Iraq. 
Data were collected through a special questionnaire regarding mothers age, address, education, smoking habit, history of abortion or infertility, residency (rural or urban), antenatal care visit with the number of these visits, any supplementation of tonics, any ante-partumcomplication have been evaluated and the informed consent was taken from every mother. Newborn babies were examine for gender and presence of congenital anomalies. Gestational age was determined were the full term babies ( ${ }^{3} 37$ weeks of gestation)and the birth weight was measured immediately after delivery.

The newborns divided into two groups, a case group with LBW $<2.5 \mathrm{~kg}$ and a control group with normal birth weight (NBW) of $\geq 2.5 \mathrm{~kg}$.

- Inclusion Criteria: All live babies born at termgestational age.
- Exclusion Criteria: Intra-uterine deaths, stillbirths, and twins deliveries.

The results were analyzed using Chi-squared method, where P-Value is not significant if it is $>0.05$, significant if $<0.05$, and highly significant if $<0.001$.

\section{Results}

Out of 267 term babies, there are $166(62.5 \%)$ with normal birth weight, and 101 (37.5\%) with LBW.

Table (1) shows that a mothers where maternal age $<20$ years, low maternal educational level, working mothers, smoking habit, low socioeconomic status associated with significant relation with LBW.

Table (1) Socio-demographic characteristics of 267 mothers

\begin{tabular}{|c|c|c|c|c|c|c|}
\hline \multirow{2}{*}{\multicolumn{2}{|c|}{ Age of mother }} & \multicolumn{2}{|c|}{ LBW } & \multicolumn{2}{|c|}{ NBW } & \multirow{2}{*}{ p-value } \\
\hline & & \multirow{2}{*}{$\begin{array}{c}\text { No. } \\
29\end{array}$} & \multirow{2}{*}{$\begin{array}{c}\text { \% } \\
61.7\end{array}$} & \multirow{2}{*}{$\begin{array}{c}\text { No. } \\
18\end{array}$} & \multirow{2}{*}{$\begin{array}{c}\text { \% } \\
38.3\end{array}$} & \\
\hline$<20$ years & 47 & & & & & \multirow{6}{*}{$<0.001$} \\
\hline 20-24 years & 51 & 25 & 49.1 & 26 & 50.9 & \\
\hline $25-29$ years & 43 & 21 & 48.8 & 22 & 51.2 & \\
\hline $30-34$ years & 60 & 15 & 25 & 45 & 75 & \\
\hline$\geq 35$ years & 66 & 11 & 16.6 & 55 & 83.3 & \\
\hline Total & 267 & 101 & 37.8 & 166 & 62.2 & \\
\hline \multicolumn{6}{|l|}{ Residence } & \multirow{4}{*}{$>0.05$} \\
\hline Rural & 107 & 39 & 36.4 & 68 & 63.6 & \\
\hline Urban & 160 & 62 & 38.7 & 98 & 61.3 & \\
\hline Total & 267 & 101 & 37.8 & 166 & 62.2 & \\
\hline \multicolumn{6}{|c|}{ Level of education of mother } & \multirow{7}{*}{$<0.001$} \\
\hline Illiterate & 54 & 43 & 79.7 & 11 & 20.3 & \\
\hline Primary & 50 & 33 & 66 & 17 & 34 & \\
\hline Intermediary & 36 & 13 & 36.1 & 23 & 63.9 & \\
\hline Secondary & 59 & 7 & 11.9 & 52 & 88.1 & \\
\hline University \& above & 68 & 5 & 7.4 & 63 & 92.6 & \\
\hline Total & 267 & 101 & 37.8 & 166 & 62.2 & \\
\hline \multicolumn{6}{|l|}{ Employment-status } & \multirow{4}{*}{$<0.001$} \\
\hline Worker & 112 & 83 & 74.1 & 29 & 25.9 & \\
\hline House-wives & 155 & 11.6 & 17.9 & 137 & 88.4 & \\
\hline Total & 267 & 101 & 37.8 & 166 & 62.2 & \\
\hline
\end{tabular}




\begin{tabular}{|c|c|c|c|c|c|c|}
\hline \multirow{2}{*}{\multicolumn{2}{|c|}{ Age of mother }} & \multicolumn{2}{|c|}{ LBW } & \multicolumn{2}{|c|}{ NBW } & \multirow{2}{*}{ p-value } \\
\hline & & No. & $\%$ & No. & $\%$ & \\
\hline \multicolumn{6}{|l|}{ Smoking habit } & \multirow{5}{*}{$<0.001$} \\
\hline Non- smoker & 112 & 16 & 14.3 & 96 & 85.7 & \\
\hline Passive smoker & 82 & 36 & 43.9 & 46 & 56.1 & \\
\hline Current Smoker & 73 & 49 & 67.1 & 24 & 32.9 & \\
\hline Total & 267 & 101 & 37.8 & 166 & 62.2 & \\
\hline \multicolumn{6}{|c|}{ Socioeconomic status } & \multirow{5}{*}{$<0.001$} \\
\hline High & 108 & 15 & 14.9 & 93 & 56 & \\
\hline Moderate & 66 & 21 & 20.8 & 45 & 27.1 & \\
\hline Low & 93 & 65 & 64.3 & 28 & 16.9 & \\
\hline Total & 267 & 101 & 37.8 & 166 & 62.2 & \\
\hline
\end{tabular}

As shown in table (2), pre-delivery weight (less than 50k.g.), maternal height $(\leq 150 \mathrm{~cm})$ and short-spacing $(<1$ year) associated with significant relation with LBW.

Table (2) Clinical aspects related to mothers

\begin{tabular}{|c|c|c|c|c|c|c|}
\hline \multirow{2}{*}{\multicolumn{2}{|c|}{ Pre-pregnancy weight }} & \multicolumn{2}{|c|}{ LBW } & \multicolumn{2}{|c|}{ NBW } & \multirow{2}{*}{ p-value } \\
\hline & & \multirow{2}{*}{$\begin{array}{c}\text { No. } \\
29\end{array}$} & \multirow{2}{*}{$\begin{array}{c}\frac{\%}{0} \\
61.7\end{array}$} & \multirow{2}{*}{$\begin{array}{c}\text { No. } \\
18\end{array}$} & \multirow{2}{*}{$\begin{array}{c}\text { \% } \\
38.3\end{array}$} & \\
\hline$<50 \mathrm{~kg}$ & 47 & & & & & \multirow{4}{*}{$<0.001$} \\
\hline $50-89 \mathrm{~kg}$ & 149 & 51 & 34.2 & 98 & 65.8 & \\
\hline$\geq 90 \mathrm{~kg}$ & 71 & 21 & 29.6 & 50 & 70.4 & \\
\hline Total & 267 & 101 & 37.8 & 166 & 62.2 & \\
\hline \multicolumn{6}{|c|}{ Maternal height cm } & \multirow{4}{*}{$<0.001$} \\
\hline$\leq 150$ & 95 & 63 & 66.3 & 32 & 33.7 & \\
\hline$>150$ & 172 & 38 & 22.1 & 134 & 77.9 & \\
\hline Total & 267 & 101 & 37.8 & 166 & 62.2 & \\
\hline \multicolumn{6}{|l|}{ Parity } & \multirow{5}{*}{$<0.005$} \\
\hline Prime & 110 & 52 & 51.5 & 58 & 35 & \\
\hline $2-3$ & 73 & 28 & 38.4 & 45 & 61.6 & \\
\hline$>3$ & 84 & 21 & 25 & 63 & 75 & \\
\hline Total & 267 & 101 & 37.8 & 166 & 62.2 & \\
\hline \multicolumn{6}{|c|}{ Spacing(years) } & \multirow{6}{*}{$<0.001$} \\
\hline$<1$ & 31 & 26 & 46.4 & 5 & 7.0 & \\
\hline 1 & 25 & 14 & 25 & 11 & 15.5 & \\
\hline 2 & 34 & 11 & 19.6 & 23 & 32.4 & \\
\hline$\geq 3$ & 37 & 5 & 9.0 & 32 & 45.1 & \\
\hline Total & 127 & 56 & 44.1 & 71 & 55.9 & \\
\hline
\end{tabular}


Table (3) Distribution of the birth weight according to the mothers previous obstetrical history

\begin{tabular}{|c|c|c|c|c|c|c|}
\hline \multirow{2}{*}{\multicolumn{2}{|c|}{ Previous obstetrical history }} & \multicolumn{2}{|c|}{ LBW } & \multicolumn{2}{|c|}{ NBW } & p-value \\
\hline & & No. & $\%$ & No. & $\%$ & \multirow{5}{*}{$<0.001$} \\
\hline \multirow{4}{*}{1} & \multicolumn{5}{|c|}{ History of previous LBW deliveries* } & \\
\hline & Yes & 28 & 68.3 & 45 & 40.1 & \\
\hline & No & 13 & 31.7 & 67 & 59.9 & \\
\hline & Total & 41 & 26.6 & 112 & 37.4 & \\
\hline \multirow{4}{*}{2} & \multicolumn{5}{|l|}{ History of stillbirth* } & \multirow{4}{*}{$<0.001$} \\
\hline & Yes & 37 & 77.1 & 26 & 24.8 & \\
\hline & No & 11 & 22.9 & 79 & 75.2 & \\
\hline & Total & 48 & 31.4 & 105 & 68.6 & \\
\hline \multirow{4}{*}{3} & \multicolumn{5}{|c|}{ History of $1^{\text {st }}$ week neonatal death* } & \multirow{4}{*}{$<0.001$} \\
\hline & Yes & 31 & 57.4 & 21 & 21.2 & \\
\hline & No & 23 & 42.6 & 78 & 78.8 & \\
\hline & Total & 54 & 35.3 & 99 & 64.7 & \\
\hline \multirow{4}{*}{4} & \multicolumn{5}{|l|}{ History of infertility } & \multirow{4}{*}{$<0.001$} \\
\hline & Yes & 62 & 61.4 & 45 & 27.1 & \\
\hline & No & 39 & 38.6 & 121 & 72.9 & \\
\hline & Total & 101 & 37.8 & 166 & 62.2 & \\
\hline \multirow{4}{*}{5} & History of abortion & & & & & \multirow{4}{*}{$>0.05$} \\
\hline & Yes & 21 & 20.8 & 44 & 26.5 & \\
\hline & No & 80 & 79.2 & 122 & 73.5 & \\
\hline & Total & 101 & 37.8 & 166 & 62.2 & \\
\hline
\end{tabular}

*After exclusion of primiparous (114) from total number (267), the remain number (153).

As shown in table (3), mothers who had delivered LBW babies previously, (68.3\%) gave birth to LBW babies again. The risk of giving birth to LBW babies significantly increased in mothers with history of still birth $(77.1 \%)$, previous history of first week neonatal death $(57.4 \%)$ and history of infertility $(61.4 \%)$.

Table (4) Distribution of the birth weight according to the mother attendance to antenatal care centers

\begin{tabular}{|c|c|c|c|c|c|c|}
\hline \multirow{2}{*}{\multicolumn{2}{|c|}{ ANC attendance }} & \multicolumn{2}{|c|}{ LBW } & \multicolumn{2}{|c|}{ NBW } & \multirow{2}{*}{ p-value } \\
\hline & & No. & $\%$ & No. & $\%$ & \\
\hline \multirow{4}{*}{1} & \multicolumn{5}{|c|}{ Antenatal care } & \multirow{4}{*}{$\leq 0.001$} \\
\hline & Absent & 26 & 25.8 & 24 & 14.5 & \\
\hline & Present & 75 & 74.2 & 142 & 85.5 & \\
\hline & Total & 101 & 37.8 & 166 & 62.2 & \\
\hline \multirow{5}{*}{2} & \multicolumn{5}{|c|}{\begin{tabular}{|l|} 
Number of visits \\
\end{tabular}} & \multirow{5}{*}{$<0.001$} \\
\hline & $1-3$ & 35 & 46.7 & 11 & 7.7 & \\
\hline & $4-6$ & 21 & 28.0 & 51 & 35.7 & \\
\hline & $\geq 7$ & 19 & 25.3 & 81 & 56.6 & \\
\hline & Total & 75 & 31.9 & 143 & 68.1 & \\
\hline
\end{tabular}




\begin{tabular}{|c|c|c|c|c|c|c|}
\hline \multirow{2}{*}{\multicolumn{2}{|c|}{ ANC attendance }} & \multicolumn{2}{|c|}{ LBW } & \multicolumn{2}{|c|}{ NBW } & \multirow{2}{*}{ p-value } \\
\hline & & \multirow[t]{2}{*}{ No. } & \multirow[t]{2}{*}{$\%$} & \multirow[t]{2}{*}{ No. } & \multirow[t]{2}{*}{$\%$} & \\
\hline \multirow{5}{*}{3} & Date of $1^{\text {st }}$ visit & & & & & \multirow{5}{*}{$<0.005$} \\
\hline & $1^{\text {st }}$ trimester & 15 & 20.0 & 59 & 41.3 & \\
\hline & $2^{\text {nd }}$ trimester & 26 & 34.7 & 44 & 30.8 & \\
\hline & $3^{\text {rd }}$ trimester & 34 & 45.3 & 40 & 27.9 & \\
\hline & Total & 75 & 31.9 & 143 & 68.1 & \\
\hline \multirow{4}{*}{4} & \multicolumn{5}{|c|}{ Iron-folate supplementation } & \multirow{4}{*}{$<0.005$} \\
\hline & No & 58 & 77.3 & 58 & 40.6 & \\
\hline & Yes & 17 & 22.7 & 85 & 59.4 & \\
\hline & Total & 75 & 31.9 & 143 & 68.1 & \\
\hline
\end{tabular}

As shown in table (4). Significant association was found between the number of visits to ANC center and giving LBW-babies. The mothers who was not received iron-folate supplementation were significantly at higher risk of giving LBW babies.

\section{Discussion}

In this study a significant association was observed between the age and fetal growth were mothers less than 20 years old gave birth to a LBW babies. Similar finding was observed by Althabe et al study ${ }^{7}$. This could be explained by the fact that such teenagers have not completed their physical growth and the additional caloric requirement of the pregnancy may create a competition between the mother and the fetus for nutrients.

human health may be effected by environmental exposures but no significant association was found between residence and fetal growth. This is in agreement with the study of Domple ${ }^{8}$.

The present study showed that as the maternal educational level increases, the chance of delivering LBW neonate decreases, the same result was reported in Pakistan ${ }^{9}$.

working mothers were more prone to deliver LBW neonates, this is partially may explained by the lack of the time needed for mother to rest and that exercise during work may reduce blood flow from the uterus to the placenta. This result coincides with study carried out in Tehran which illustrate that LBW among employed mothers was 5 times more likely than unemployed ones ${ }^{10}$.
In our study, there is a significant association between cigarette smoking and delivering LBW neonate. This finding was consistent with the finding reported byZheng et al ${ }^{11}$.

Maternal pre-pregnancy weight status has an important rule on fetal growth and the ability of the placenta to supply essential nutrients to the fetus depends on the nutritional status of the mother ${ }^{12}$. This study show that women with low pre-pregnancy weight $(<50 \mathrm{k.g})$ were more prone to deliver small babies. the same result was reported byZ. He et al ${ }^{13}$.

Maternal height also revealed significant association with LBW babies, women whose height were less than or $=150 \mathrm{~cm}$ appeared to be significantly at higher risk of having LBW-babies. This might be explained by genetic susceptibility. This result was in accordance with the finding in study in 2015 in Nepal ${ }^{14}$.

The LBW babies were more likely to be the first born baby. This might be explained by the fact that multiparous women know more about how to deal with their pregnancy. This finding was similar to that found byRosy et $\mathrm{al}^{15}$.

Result demonstrated that those mothers with low SES were more prone to delivering LBW neonate when compared with high SES mothers. The logic explanation for this finding is that mothers with low SES may not attended health care and with poor nutrition. This result supports that reported by Rosy et $\mathrm{al}^{15}$.

This study showed that there was a significant association between short spacing and LBW babies. This might be due to nutritional deprivation and incomplete 
return of the maternal physiology to normal levels encountered among rapid conceivers. similar finding were reported by other studies in India ${ }^{16}$.

Mother with history of previous LBW delivery are more likely to having LBW neonates in subsequent pregnancy. This finding was also obtained byMvunta et $\mathrm{al}^{17}$. The explanation of this finding may be due to the persistence of socio-demographic factors like age, poor nutritional and social status.

The study also clarified a significant risk of LBW in pregnancy preceded by history of stillbirth or first week neonatal death. This finding was compatible to that found by Feresu ${ }^{18}$.

Compared with infants conceived within 12 months of trying, those conceived after a waiting time of 12 months have a higher risk of preterm birth and $\mathrm{LBW}^{19}$. Mothers with history of infertility were more prone to deliver LBW-babies. This finding was in agreement with the study of Wannous et al in Syria ${ }^{20}$.

Regarding previous history of abortion, no significant association was found with LBW babies, this finding support the finding detected in Syria ${ }^{20}$.

Prenatal care considered an important tools available to detect obstetric risk factors that may impact on optimal fetal development, and final birth weight ${ }^{21}$ Mothers with no antenatal care, were more prone to deliver LBW babies this was in agreement with that found by Howlader ${ }^{22}$.

The prevalence of LBW significantly affected by micronutrient deficiencies during pregnancy, particularly iron and folate ${ }^{23}$. This study detected that nutritional supplementation with iron and folate during pregnancy was associated with reducing the risk of giving LBW neonate. This finding was in agreement with that observed by Howlader ${ }^{22}$.

\section{Conclusion}

The study showed the maternal risk factors for LBW neonates were maternal age 20 years, low maternal educational level, working mothers, smoking habit, pre-delivery weight (less than $50 \mathrm{~kg}$ ), maternal height $(\leq 150 \mathrm{~cm})$, low socioeconomic status and short-spacing (1 year), less frequent and late visits to ANC-centers and with no supplementation of iron and folate. Previous bad obstetrical history is a probable risk factor.

\section{Conflict of Interest:}

\section{Source of Funding: Self}

Ethical Clearance: Not required

\section{References}

1. World Health Organization. Global nutrition targets 2025: Stunting policy brief. World Health Organization; 2014.

2. Ballot DE, Potterton J, Chirwa T, Hilburn N, Cooper PA. Developmental outcome of very low birth weight infants in a developing country. BMC pediatrics. 2012 Dec 1;12(1):11.

3. Choudhary AK, Choudhary A, Tiwari SC, Dwivedi R. Factors associated with low birth weight among newborns in an urban slum community in Bhopal. Indian journal of public health. 2013 Jan 1;57(1):20.

4. Bharati P, Pal M, Bandyopadhyay M, Bhakta A, Chakraborty S. Prevalence and causes of low birth weight in India. Malaysian Journal of Nutrition. 2011 Dec 1;17(3).

5. Mahumud RA, Sultana M, Sarker AR. Distribution and determinants of low birth weight in developing countries. Journal of preventive medicine and public health. 2017 Jan;50(1):18.

6. Deshpande Jayant D, Phalke DB, Bangal VB, D Peeyuusha BS. Maternal risk factors for low birth weight neonates: a hospital based casecontrol study in rural area of western maharashtra, India. National Journal of Community Medicine. 2011 Oct;2(3):394-8.

7. Althabe F, Moore JL, Gibbons L, Berrueta M, Goudar SS, Chomba E, Derman RJ, Patel A, Saleem S, Pasha O, Esamai F. Adverse maternal and perinatal outcomes in adolescent pregnancies: The Global Network's Maternal Newborn Health Registry study. Reproductive health. 2015 Dec $1 ; 12(\mathrm{~S} 2): \mathrm{S} 8$.

8. Domple VK, Doibale MK, Nair A, Rajput PS. Assessment of maternal risk factors associated with low birth weight neonates at a tertiary hospital, Nanded, Maharashtra. Nigerian medical journal: journal of the Nigeria Medical Association. 2016 Jan;57(1):37.

9. Dayanithi M. Low birth weight and premature births and their associated maternal factors. Int J Community Med Public Health. 2018 Jun;5(6):2277. 
10. Mahmoodi Z, Karimlou M, Sajjadi H, Dejman M, Vameghi M, Dolatian M, Mahmoodi A. Association of maternal working condition with low birth weight: The social determinants of health approach. Annals of medical and health sciences research. 2015;5(6):385-91.

11. Zheng W, Suzuki K, Tanaka T, Kohama M, Yamagata Z, Okinawa Child Health Study Group. Association between maternal smoking during pregnancy and low birthweight: effects by maternal age. PloS one. 2016 Jan 21;11(1):e0146241.

12. Field ME, Anthony RV, Engle TE, Archibeque SL, Keisler DH, Han H. Duration of maternal undernutrition differentially alters fetal growth and hormone concentrations. Domestic animal endocrinology. 2015 Apr 1;51:1-7.

13. He Z, Bishwajit G, Yaya S, Cheng Z, Zou D, Zhou Y. Prevalence of low birth weight and its association with maternal body weight status in selected countries in Africa: a cross-sectional study. BMJ open. 2018 Aug 1;8(8):e020410.

14. Shakya KL, Shrestha N, Kisiju P, Onta SR. Association of maternal factors with low birth weight in selected hospitals of Nepal. Journal of Nepal Health Research Council. 2015 Dec 31.

15. Rosy N, Sultana N, Naher L, Pervin Z, Das SK, Islam MM, Khair MA, Arif KM. Risk factors of low birth weight baby. Faridpur Medical College Journal. 2018 Aug 24;13(1):31-4.

16. Fourie N, du Rand SM, Morton DG. Risks of preterm labour among women who attend public antenatal care clinics. Africa Journal of Nursing and Midwifery. 2018 Jun 1;20(1):1-6.
17. Mvunta MH, Mboya IB, Msuya SE, John B, Obure J, Mahande MJ. Incidence and recurrence risk of low birth weight in Northern Tanzania: A registry based study. Plos one. 2019 Apr 22;14(4):e0215768.

18. Feresu SA, Harlow SD, Woelk GB. Risk factors for low birthweight in Zimbabwean women: a secondary data analysis. PloS one. 2015 Jun 26;10(6):e0129705.

19. Jaques AM, Amor DJ, Baker HG, Healy DL, Ukoumunne OC, Breheny S, Garrett C, Halliday JL. Adverse obstetric and perinatal outcomes in subfertile women conceiving without assisted reproductive technologies. Fertility and sterility. 2010 Dec 1;94(7):2674-9.

20. Wannous S, Arous S. Incidence and determinants of low birth weight in Syrian government hospitals. EMHJ-Eastern Mediterranean Health Journal, 7 (6), 966-974, 2001. 2001.

21. Pinzón-Rondón ÁM, Gutiérrez-Pinzon V, Madriñan-Navia H, Amin J, Aguilera-Otalvaro P, Hoyos-Martínez A. Low birth weight and prenatal care in Colombia: a cross-sectional study. BMC pregnancy and childbirth. 2015 Dec 1;15(1):118.

22. Howlader M, Hossain MS. MS Relationship among Antenatal Care Practices and Socioeconomic Factors with Birth Weight of Neonates in Dhaka City. Journal of Gynecology and Women's Health.;8.

23. Elhassan EM, Abbaker AO, Haggaz AD, Abubaker MS, Adam I. Anaemia and low birth weight in Medani, Hospital Sudan. BMC research notes. 2010 Dec;3(1):1-5. 